\title{
C.S.I.R.O. DIVISION OF PROTEIN CHEMISTRY, MELBOURNE
}

$\mathrm{O}^{\mathrm{N}}$ October 25, 1963, a new laboratory block was opened in Melbourne for the Division of Protein Chemistry by the Minister-in-Charge of the Commonwealth Scientific and Industrial Research Organization, Scnator the Hon. J. G. Gorton. Situated in Royal Parade, Parkville, on a tree-lined highway leading to the city, the Division is conveniently close to the University of Melbourne, medical research institutes and other e.S.I.R.O. divisions. The absence of industrial activity in the area and the parks adjacent to the site ensure a clean atmosphere and a good environment for research.

The Division of Protein Chemistry was established in 1949 as one unit of the C.S.I.R.O. Wool Research Laboratories, the other two being the Division of Textile Physics in Sydney and tho Division of Toxtile Industry in Geelong. The Division was transferred from temporary premises in the city of Molbourne to tho present site in 1952. Here it has been accommodated in two converted residences supplemented by a two-storey building. The new sixstorey block (Fig. 1) provides approximately 29,000 sq. ft. of floor space, and it is planned ultimately to demolish the old residences and extend the new block to double its present size.

Since the formation of C.S.I.R., the fororunner of C.S.I.R.O., in the 1920 's, several of the primary industry divisions have been engaged in research to improve wool production. Extension of this work to wool utilization is a relatively recent development. It was made in recognition of the fact that the wool grower, like the producers of other textile fibres, must promote his product technically.

The main responsibility of the Division is to use protein chemistry and associated branches of science to enhance knowledge of the structure and chemistry of wool and to suggest how new information about the fibre might be put to immediate technical advantage in the industry.

The professional staff of the Division includes forty-five science graduates-thirty research officers and fifteen experimental officers-covering the disciplines of biochemistry, physical chemistry, organic chemistry, biophysics and microbiology. Of these research workers eight hold threerear post-doctoral fellowships.

The ground floor of the new building accommodates physical shemistry equipment including an analytical centrifuge, moving boundary electrophoresis apparatus, and apparatus for light scattering, optical rotatory dispersion, surface balance, radiotracer and spectroscopy investigations. The library, staff-room and lecture theatre occupy the first floor, biochemical laboratories the second floor, and organic chemistry laboratories the third floor. The fourth floor is expected to be used for research on collagen, myosin, and similar protein projects not financed from wool funds.

An unusual feature is the provision of internal rooms along one side of the passage on each floor for use as dark rooms, constant temperature and constant humidity rooms, for balances, spectrophotometers and other hared apparatus, and for textile testing.

Facilities for electron microscopy, X-ray diffruction, amino-acid analysis, microbiology, small-scale textile procossing and chemical and apparatus stores, are located in the two-storey building referred to earlier. Administration activities are accommodated in one of the old residences and instrument workshops in the other.

To bring a variety of techniques to focus on a particular project, groups have been formed in the Division each of which includes representatives of several disciplines. The present groups deal with the structure, proteins, chemistry, yellowing and processing of wool and with the wool follicle. In addition to day-to-day collaboration members of each group meet together every two months to survey progress and to plan research for the ensuing period. The arrangement is very floxible. Research staff may belong to one or more groups, and the number and scope of the groups are varied from time to time to meet the changing needs of the research programme.

Research in the Division is partly concernod with investigations of wool structure using techniques which are applicable to the intact fibre. Electron microscopy and $X$-ray diffraction investigations have revealod the presence of microfibrils, approximately $80 \AA$ in diameter, embedded

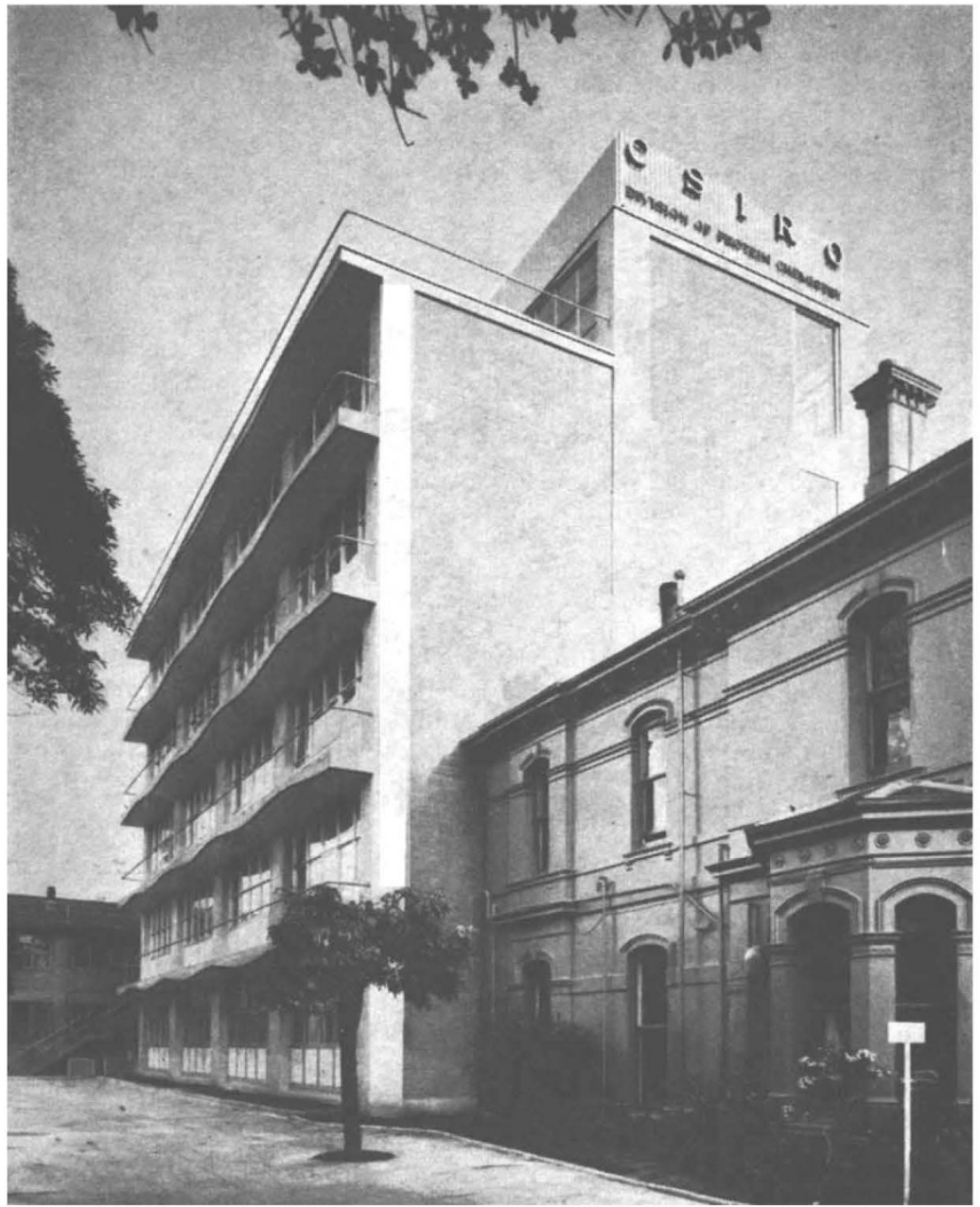

Fig. 1. New Laboratory Building at the C.S.I.R.o. Division of Protein Chemistry Parkville, Melbourne 


\section{№. 4917 January 25,1964 N A T U R E}

in an amorphous matrix. Recent investigations have shown the presence of an array of about eleven protofibrils, each $20 \AA$ in diameter, inside each microfibril. The results from the X-ray investigations suggest a segmented rope structure for each protofibril in which the strands consist of a succession of short lengths of $\alpha$-helix. The number of strands in the rope is believed to be three.

Another phase of the wool structure programme is concerned with the extraction of proteins from the fibre and their fractionation and characterization. Rupture of the disulphide bonds in wool may be accomplished by performic acid oxidation, sulphitolysis with sodium bisulphite, or oxidative sulphitolysis through the combined action of bisulphite and a mild oxidizing agent. However, thioglycollato reduction and extraction under mildly alkaline conditions is the method most commonly used. Oxidation of the reduced proteins is prevented by treatment with iodoacetate which reacts with the sulphydryl groups. Low-sulphur and high-sulphur protein fractions are obtained from the mixed $S$-carboxymethyl wool proteins. The low-sulphur proteins are believed to come from the microfibrils, and optical rotatory dispersion measurements indicate that they contain 50 per cent $\alpha$-helix. The high-sulphur proteins are believed to come from the matrix and they contain little or no helical protein. Fractionation of the high-sulphur proteins has been moro successful than of the low-sulphur proteins, and two of the high-sulphur protein preparations are believed to be relatively pure. Both contain more cystine, serine, threonine and proline than wool and one is almost devoid of lysine and histidine.

Amino-acid analysis figures strongly in the work of the Division and is used, for example, for following chemical changes in wool and for characterizing wool proteins. In addition to a single column ion-exchange resin automatic machine a nine-column automatic machine has been designed and largely constructed in the Division: it yields nine complete analyses in two days. Methods have been developed of estimating cystine and cysteine in the intact fibre based on amperometric titration, and a radioactive tracer technique is now also available for estimating cysteine in fragments from a single Merino fibre. The estimation of lanthionine in protein hydrolysates has been speeded up and improvements have been made in the method of estimating tryptophan. Determ. ination of acetyl groups in wool indicates that they mask the majority of $N$-terminal groups in the fibre.

Photochemical damage to wool causes yellowing and is produced by ultra-violet radiation from the Sun. Research to develop a method of preventing yellowing has met with partial success and experiments are in hand to determine whether the method is likely to find commercial application. Analysis of yellowed wool reveals partial destruction of tryptophan, tyrosine and cystine, but the chemical nature of the yellow product responsible for the discoloration is not yet known. Research on the photochemistry, chemical reactivity ard structure of wool is supported by investigations on cystine, tryptophan and the other amino-acids of wool, and on synthetic peptides and their derivatives.

The wax sheet method of collecting wool roots developed in the Division in 1948 has enabled the proteins of the roots and the associated enzymes and metabolites to be investigated. Low- and high-sulphur protein fractions can be prepared from wool roots as for the fully keratinized fibre, although the sulphur contents of the fractions aro appreciably lower than the corresponding fractions from wool. Citrulline has been detected in peptide combination in a protein obtained from the inner root sheath. Wool root extracts have been found to contain free aminoacids, all the components of tho citric acid cycle, and the enzymes phosphatase (especially pyrophosphatase), aminoacid dehydrogenases, esterase, catalase, transaminase and transpeptidase.

Research on the structure and chemistry of wool and other proteins is already having an impact on the wool industry. Investigations of the hydrothermal shrinkage of collagen and subsequent ease of proteolytic enzyme and bacterial digestion led to the development of a method of digesting sheepskin pieces and damaged, wrinkly or short-wooled skins for the recovery of the wool. The method is now in use in several Australian fellmongeries. Observations on the protection of soluble proteins against damage suggested a commercial procedure for protecting wool against damage during carbonizing. It involves the addition of a certain type of non-ionic wetting agent to the sulphuric acid bath in which the burry wool is soaked before drying and baking. A third illustration of benefits for the wool industry arising from protein investigations is the development of the formic acid dyeing process. This method stemmed from the observation that formic acid has a remarkably good swelling and disaggregating action on the extracted wool proteins. Formic acid solutions of dyes likewise swell the fibre and allow the dye molecules to enter. Swelling is reversed by washing in water but the dye is held in the fibre. The method is now used commercially for printing patterns on wool blankets and its application to top dyeing is being developed in the C.S.I.R.O. Division of Chemical Engineering.

A number of projects of direct practical importance have been undertaken. It has been found, for example, that the accumulation of wool wax on shearing combs can be prevented by the application of a layer of polytetrafluoroethylene to the lower surface, and the vacuum pressing method of packing wool in a polythene bag before inserting it in the jute bale reduces jute contamination and facilitates handling. The felt moulding process of felting wool to desired patterns in sheets or to threedimensional articles such as berets and mittens has commercial potential, and the selection, dyeing and tanning of sheepskins for use in hospitals and institutions for tho comfort and protection of patients against the development of bed-sores are increasing in popularity. The boiling of all-wool shrinkproofed hospital blankets in a special detergent to extend their life to three hundred or more laundry eycles is now standard practice in most Australian hospital launderies.

Sharing the resources of the Division between research on the structure and chemistry of wool and on problems of immediate practical importance to the wool industry has produced an interplay of ideas and stimulus that is mutually advantageous to both aspects of the overall programme.
F. G. Lennox

\section{SCIENTIFIC RESEARCH IN AUSTRALIA}

$\mathrm{T}$ HE fifteenth annual report of the Commonwealth Scientific and Industrial Research Organization*, covering the year ended June 30,1963 , follows the pattern of recent years. To a general review of the year and a

* Australia: Commonwealth Scientific and Industrial Research Organization. Fifteenth Annual Report, 1962-63. Pp. iv $+162+25$ photographs. (Melbourne: Commonwealth Scientific and Industrial Research Organization, 1963.) brief account of significant developments in research, a list of published papers (nearly 50 pages) and lists of members of the Advisory Council, State committees and staff are appended, together with the financial statement. The report is illustrated.

Expenditure during the year amounted to nearly £13 million, the major items being $f 1$ million on the National Standards Laboratory, $£ 1 \cdot 35$ million on physical and 